\title{
Simulação do ambiente natural na sala de aula: tecnologia como alternativa para o desenvolvimento da percepção ambiental
}

\author{
Simulation of natural environment in the classroom: technology as an \\ alternative for the development of environmental perception
}

\author{
1 Raquel Lacerda raquelacerda29@gmail.com \\ 2 Maria da Conceição Vinciprova Fonseca
}

1 Mestre em Ensino em Ciências da Saúde e do Meio Ambiente, UniFOA.

2 Docente do Centro Universitário de Volta Redonda, UniFOA.

\section{Resumo}

Dada a relevância dos temas que envolvem a educação ambiental e a dificuldade de acesso aos parques e santuários ecológicos, especialmente em se tratando de crianças pequenas, o presente estudo teve como objetivo estimular a percepção ambiental em alunos das séries iniciais do ensino fundamental, desenvolvendo, para tal, um aplicativo computacional - Simulacron - contendo imagens e sons da natureza, destinado a simular o ambiente natural na sala de aula. 0 produto foi testado em uma pesquisa com alunos de quatro turmas do primeiro ano do Ensino Fundamental, que participaram de um esquema de aulas diferenciadas em que três turmas tiveram momentos de atividades lúdicas sensório-perceptivas em ambiente natural e/ou simulada na sala de aula, e uma turma não teve acesso a qualquer ação. Em uma segunda etapa, os alunos das quatro turmas produziram, na aula de Artes, desenhos, tendo como tema o Meio Ambiente, que constituíram o corpus para a análise, realizada segundo Pedrini e Reigota. Os resultados mostraram a eficácia do aplicativo, gerando resultados na mesma ordem de grandeza daqueles obtidos com atividades in loco e superiores aos resultados da turma que não participou de qualquer ação.

\section{Palavras-chave}

percepção ambiental; ensino; desenho; aplicativo computacional.

\begin{abstract}
Given the relevance of issues involving environmental education and the difficulty of access wildlife sanctuaries especially when it comes to young children this study aimed to stimulate environmental awareness in students from the first grade of elementary school developing a computational application - Simulacron - containing images and sounds of nature intended to simulate the natural environment in the classroom. The product was tested with students from four groups of the first grade of elementary school, who participated in a scheme of differentiated classes in which three groups had moments of sensory-perceptive activities in a natural environment and/or simulated in the classroom and a group had no access to any action. In a second moment the students of the four groups produced drawings having as theme the environment in an art class which formed the corpus for the analysis made according Pedrini and Reigota. The results showed the application effectiveness which generated results in the same order as those obtained with activities in loco and higher than the class results that did not participate in any action.
\end{abstract}

\section{Keywords}

environmental awareness; teaching; drawing; multimedia app.

\section{Como você deve citar?}

LACERDA, Raquel; FONSECA, Maria da Conceição Vinciprova. Simulação do ambiente natural na sala de aula: tecnologia como alternativa para o desenvolvimento da percepção ambiental. Cadernos UniFOA, Volta Redonda, n. 31, p. 87-100, ago., 2016. 


\section{INTRODUÇÃO}

Dada a relevância dos temas que envolvem Educação Ambiental e sustentabilidade, é imperativo que a criança em idade escolar tenha acesso a esses conceitos, para que possam fazer parte da formação do seu caráter.

A região de Volta Redonda é reconhecidamente uma área voltada para as atividades industriais. Entretanto, também possui áreas de preservação ambiental que devem ser conhecidas e exploradas para que as questões ambientais possam ser percebidas, servindo como um contraponto ao paradigma local, de indústria e tecnologia. Mas sabe-se da dificuldade em ir a esses locais, em vista da necessidade de professores para controlar as crianças, da autorização por escrito dos pais, do risco de acidentes, de conseguir transporte adequado e muitos outros fatores.

Desse modo, coloca-se a questão de como sensibilizar crianças para otimizar as possibilidades de desenvolvimento de sua consciência ambiental.

O desenvolvimento de ações voltadas às questões ambientais é importante, não só para a formação do sujeito, trabalhando a construção dos conceitos de ecologia, responsabilidade e sustentabilidade, mas também para cumprir o requisito estabelecido pelos Parâmetros Curriculares Nacionais (PCNs) sobre o Meio Ambiente (1997), que urgem levar o aluno a perceber-se como parte integrante do meio ambiente.

Diante do exposto, intentamos desenvolver um aplicativo computacional que possa complementar, potencializar ou até mesmo substituir aulas in loco. Acreditamos que tal ferramenta de ensino seja de grande valia, já que facilita o desenvolvimento de projetos e ações em educação ambiental. Criamos assim o produto resultante deste trabalho, o aplicativo Simulacron, para simular, com imagens e sons, uma experiência na natureza.

Para experimentar o aplicativo, grupos de alunos tiveram aulas em espaço ambientalmente preservado e depois com o Simulacron; outros tiveram aula apenas com o Simulacron; e outros, ainda, não tiveram experiências. Todos os grupos, ao fim, tiveram uma aula de Artes em que fizeram desenhos sobre o tema meio ambiente. Em todas as aulas, aconteceram atividades sensório-perceptivas, visando enfatizar para os alunos as experiências sensoriais, bem como desenvolver sua capacidade criativa e de imaginação através da produção de desenhos. Assim acreditamos possibilitar o entrelaçamento das histórias cultural e natural, sintetizadas nos desenhos sobre o que observaram e apreenderam. As atividades propostas contribuem para o desenvolvimento da percepção dos alunos, tornando-os observadores atentos do lugar ao qual pertencem, reforçando a esperança de que aflore neles o sentimento de ligação com a natureza.

\section{O SENTIDO DA ECOLOGIA - A EDUCAÇÃO AMBIENTAL E SUAS APLICAÇÕES}

A problemática ambiental está presente nas diferentes sociedades, de forma mais consistente, somente há algumas décadas. 0 sistema de produção e a ciência mecanicista impulsionaram os desenvolvimentos econômico e científico, originando novas estruturas de poder e novos problemas políticos, sociais e ambientais, disseminando um período de crises nos diversos setores da sociedade atual. Morin (1996), partindo da análise da crise da modernidade, denomina como "paradigma da simplificação" tudo que esteve na base dos avanços tecnológicos e da ciência nos últimos 400 anos, ou seja, os modelos de organização e produção, bem como da transmissão do saber. 
Baseados no que foi apresentado, podemos entender que a crise ambiental e global que vivemos está diretamente relacionada aos meios de produção e de consumo do sistema capitalista, assim como está a educação, que, por meio da escola, reproduz o modelo de pensamento que molda a visão de mundo.

Em tais circunstâncias, houve a necessidade de trazer para a educação reflexões sobre as principais causas da atual crise ambiental. Assim, a educação ambiental - EA - se estabeleceu a partir da segunda metade do século XX, com o surgimento do movimento ambientalista. No Brasil, isso ocorreu a partir da década de 1970, com a criação dos primeiros cursos de pós-graduação em Ecologia. A inserção da EA representou uma possibilidade de dar respostas à problemática ambiental, principalmente no que diz respeito à degradação dos recursos naturais do planeta (TOZONI-REIS, 2008).

$\mathrm{Na}$ busca por sociedades ambientalmente mais responsáveis, encontramos, na inclusão da educação ambiental, uma estratégia para alcançar esse objetivo. A partir de ações educativas que estimulam o pensamento crítico, a imaginação ecológica, a consciência das interligações e os bons sentimentos, existe a possibilidade de proporcionar mudanças nas relações entre o homem e o meio socioambiental, proporcionando uma melhoria na qualidade de vida.

Jacobi (2003) argumenta sobre a importância de uma ação holística em que estejam relacionados o homem, a natureza e o universo, sem perder de vista que os recursos naturais se esgotam, tendo como principal agente da degradação o ser humano. Com isso, seria possível resgatar para a disciplina da educação a sua real importância, que é tratar a grande questão de como viver, ou seja, de que fazemos parte da comunidade una e indivisível da vida.

Sabemos que aquilo que se faz com prazer, se faz melhor, bem como aquilo que se aprende com prazer, se aprende melhor. Mesmo cientes da existência de muitos fatores que têm afastado os professores da docência, podemos afirmar que o envolvimento prazeroso nos seus cotidianos pode ajudar a reverter o quadro da atualidade, em que se vê o crescente adoecimento e perda de interesse em lecionar. Como afırma Gadotti (2002, p. 27), "um dos segredos do chamado 'bom professor' é trabalhar com prazer, gostando do que se faz. A gente faz sempre bem o que gosta de fazer. Só é bem sucedido aquele ou aquela que faz o que gosta."

Então, o resgate do prazer e da beleza da vida cotidiana através da exploração estética da natureza pode ser uma maneira de trazer de volta seu valor intrínseco, que vai além de uma condição de mera contemplação. Segundo Tristão $(2005$, p. 10$)$ "os sentidos estéticos da natureza integram a narrativa da arte, da cultura e da educação ambiental e podem ser um mecanismo de contágio de sentimentos ou da emoção vivida em comum."

Assim, uma proposta metodológica centrada na conscientização, participação e experimentação através de atividades lúdicas sensório-perceptivas, aliadas a práticas artísticas, deverá contribuir para o aumento do conhecimento, bem como para a mudança de valores e comportamento, propiciando o aperfeiçoamento de habilidades que acreditamos serem condições necessárias para estimular a integração e harmonia dos educandos com o meio socioambiental.

\section{A ECOLOGIA dOS SENTIDOS - A PERCEPÇÃO E A PERCEPÇÃO AMBIENTAL}

Conforme destaca Capra (1996), a palavra "ecologia" é formada por dois termos gregos: oikos, que significa habitação, lar, família, e logia, que significa dizer, ler, anunciar. Então, ecologia não se refere diretamente à natureza, como costumamos pensar, mas à moradia, implicando o sentido de relação do ser humano com o meio onde vive. 
Em seus estudos sobre percepção, Maroti (1997) explica que a palavra "percepção", do latim percipere, originalmente significa pegar, notar, agarrar com a mente. Assim sendo, a percepção é uma maneira de entender, aprender e adquirir conhecimentos por meio dos sentidos.

Com relação aos sentidos, Cornell (2008) destaca que, através do toque, do olfato, do paladar, da visão e do som, comungamos diretamente com a natureza. Tuan (1980) explica que, diferentemente dos outros animais, os sentidos atuam no modo como o homem responde, reconhece e atua no mundo, ressaltando que, pelo acúmulo de informações simultâneas através dos sentidos, apreciamos a sensação de compreensão do espaço.

Sendo assim, o meio ambiente fornece estímulos que chegam até nós e são captados através dos cinco sentidos - visão, audição, tato, olfato e paladar -, que são os "portais" para o mundo da matéria. Cada estímulo externo que recebemos promove a criação de significados e interpretamos esses significados de acordo com o nosso sistema de crenças. Entendemos por sistema de crenças tudo aquilo que faz parte da formação do indivíduo, ou seja, são os aspectos culturais e sociais de cada um. As interpretações de cada indivíduo geram informações que retornam para o meio, promovendo a sua modificação. Então, estamos sempre interagindo com o meio. É um processo dinâmico em que, por meio de cada interação, nos renovamos, nunca somos os mesmos. Esse processo envolve a cognição, porque, a todo instante, recebemos informações externas e, através das nossas interpretações e reações, nos modificamos e influenciamos o meio de modos diferentes, ou seja, aprendemos.

Com estudo da percepção, buscamos entender o que o indivíduo percebe, além de promover a sensibilização e a consciência do ambiente ao redor. Nesse contexto, o desenvolvimento da percepção ambiental pode fazer com que o indivíduo atribua valores ao ambiente, e o olhar reflexivo permite uma visão holística capaz de induzir mudanças comportamentais (MARIN, 2003). Assim, contemplamos os objetivos da educação ambiental que, além do desenvolvimento da percepção ambiental, visa à conscientização dos indivíduos em relação à manutenção e conservação dos bens naturais.

De acordo com Pedrini (2010, p. 166), a percepção ambiental vem sendo estudada "por meio de várias abordagens metodológicas que, na realidade, buscam identificar a percepção cognitiva da temática ambiental, que se espera seja essencialmente reflexo do cotidiano da pessoa pesquisada". 0 autor ainda esclarece que o conceito de percepção ambiental transita entre os temas da Fisiologia, da Semiótica, passando pela Representação Social, em que apresenta diferentes visões, tais como a sacralidade, a cientificidade e o imaginário.

Complementando a reflexão acima, Vygotsky (2009) teoriza que a percepção da criança não se dá somente pela visão, mas também através da fala, que, aprendida espontaneamente por meio das interações sociais, auxilia a percepção do meio e mais tarde se torna uma representação concreta, como a escrita e o desenho. 0 aprendizado da escrita requer a compreensão da estrutura da língua para posteriormente produzi-la graficamente. 0 desenho é mais espontâneo, pois não há a preocupação com as estruturas gramaticais, podendo a criança se expressar mais livremente. 0 autor também afirma que o pensar da criança está relacionado à memória, além do seu sistema de crenças, ou seja, de suas relações sociais e culturais. A memória da criança transforma-se num método que une experiências do passado com acontecimentos do presente.

Mèredieu, em seus estudos sobre o desenho infantil, afirma: "real e imaginário indissolúveis, o pensamento mágico da criança evolui à maneira do jogo, que funciona ao mesmo tempo como simulacro e como verdade." (MÈREDIEU, 2006, p. 6). 
Então, o conjunto de percepções do real e do imaginário da criança pode ser verificado por meio de seus desenhos, permitindo observar quais são suas relações com o meio ao seu redor, suas percepções relacionadas à temática ambiental e a partir daí, desenvolver estratégias e ações mais eficazes na educação ambiental.

\section{O PODER DA ARTE - O DESENHO INFANTIL}

Chamamos de arte a maneira pela qual o homem representa o mundo ao seu redor utilizando cores, formas, texturas, palavras, ritmo e movimento, combinando sua percepção, imaginação, criatividade e a sua bagagem cultural. Sendo assim, a arte tem função indispensável na vida das pessoas por ser um fator essencial de humanização. De acordo com Coleto (2010), a arte é sentida e vivenciada de modos diferentes por adultos e crianças. Enquanto os adultos apreciam o seu valor estético, para a criança a arte é uma forma de comunicação, em que ela pode expressar o mundo ao seu redor de maneira lúdica, fazendo o que lhe dá prazer e alegria.

Quando pensamos em arte e criança, logo surge a ideia do desenho. De acordo com Goldberg, Yunes \& Freitas (2005), o desenho infantil pode ser entendido como uma maneira da criança organizar e processar informações e experiências vividas, bem como mostrar sua representação de mundo. As experiências gráficas, além de fazerem parte do crescimento psicológico, são indispensáveis para o desenvolvimento e para a formação de indivíduos sensíveis e criativos capazes de transformar a realidade.

Segundo Mèredieu (2006), a partir do final do século XIX, a psicologia experimental mostrou-se interessada pelos desenhos infantis e, posteriormente, esse interesse se diversificou para a psicologia aplicada, a pedagogia, a sociologia e a estética, com diferentes enfoques dentro desses campos. A autora esclarece que o surgimento do que hoje chamamos de "arte infantil" e o seu estudo mais aprofundado se deram na medida em que houve a difusão e o fácil acesso a novos instrumentos e materiais, proporcionando a expansão do gesto e do movimento e, assim, a criança pode tomar consciência do espaço e suas possibilidades. A partir daí, nota-se uma profunda modificação no estilo infantil.

Diversos estudos vêm adotando o desenho como estratégia metodológica para analisar e interpretar emoções e concepções relacionadas ao meio ambiente, tanto de crianças como de pré-adolescentes (REIGADA; TOZONI-REIS, 2004; FERREIRA; NETO, 2009; MATOS, 2009; PEDRINI; COSTA; GHILARDI, 2010; DOUBRAWA; NOLASCO, 2010; GARRIDO; MEIRELLES, 2014). Porém, segundo Pedrini (2010), a coleta de dados/informações não é trivial, pois depende do referencial teórico escolhido pelo pesquisador, no qual o fenômeno perceptivo pode ter inúmeras possibilidades interpretativas.

Também existem teorias com relação às etapas do desenvolvimento gráfico infantil. Luquet (1979) observou cinco fases principais: a) realismo fortuito (um ano e seis meses aos dois anos), em que a criança faz basicamente rabiscos; $b$ ) realismo fracassado (dois anos), sendo a criança mera reprodutora do seu meio, sem conseguir dirigir e limitar seus movimentos gráficos; c) realismo simbólico (três a quatro anos), em que inicia o relacionamento de um desenho com outro e o detalha; d) realismo intelectual (quatro a quase doze anos), em que expressa o que sente, e não mais apenas o que vê; e) realismo visual (por volta dos doze anos), quando começa a dar perspectiva aos seus desenhos.

Com relação à influência do meio nos processos cognitivos da criança, Mèredieu (2006, p. 3) afirma que "nunca será demais repetir: o meio em que a criança se desenvolve é o universo adulto, e esse universo age sobre ela da mesma maneira que todo o contexto social, condicionando-a ou alienando-a." Porém, Piaget (1976) coloca o papel desenvolvido pelo meio em segundo plano, o que não ocorre nos estudos de Vygotsky (2003), que considera o meio social de fundamental importância para 
a mediação da relação Homem x Meio Ambiente. 0 autor também considera de suma importância 0 papel da imaginação no desenvolvimento humano porque, ao ser capaz de imaginar, o indivíduo amplia seus limites, assimilando experiências históricas ou sociais alheias.

Com isso, entendemos que a interação da criança com o meio é primordial para o seu desenvolvimento e que, por meio de práticas artísticas, especialmente o desenho, podemos enriquecer o imaginário da criança com imagens cotidianas que possuam significados, possibilitando um contato mais sensível com o meio onde vive, partindo do autoconhecimento para o conhecimento do outro, bem como do seu ambiente, o que pode ser verificado na sua produção gráfica.

\section{METODOLOGIA}

\subsection{Condução da pesquisa}

Este trabalho constitui-se em uma pesquisa quali/quantitativa em que foi adotada a metodologia da pesquisa-ação.Tripp (2005) considera a pesquisa-ação como uma das muitas diferentes formas de investigação-ação e a define, sucintamente, como toda tentativa continuada, sistemática e empiricamente fundamentada de aprimorar a prática.

Segundo Thiollent (2002), a orientação metodológica da pesquisa-ação na área de atuação da educação permite que os pesquisadores tenham condições de produzir informações e conhecimentos de uso mais efetivo, até mesmo num nível pedagógico. Os objetivos nessa área de pesquisa são de conhecimento (reciclagem de ideias e normas), prático (produção de material didático) e produção de técnicas educacionais direcionadas aos grupos de interesse.

De acordo com Engel (2000), a pesquisa-ação é uma maneira de se fazer pesquisa em que o sujeito investiga sua própria prática, ou seja, procura unir a pesquisa à ação, com o intuito de desenvolver o conhecimento e a compreensão acerca de seu trabalho, assim iluminando sua ação prática.

Entende-se, então, que a pesquisa-ação é um instrumento valioso para professores que desejam melhorar o processo de ensino-aprendizagem no ambiente em que atuam, pois ela apresenta subsídios para a tomada de decisões, mesmo que de caráter provisório.

O projeto de pesquisa foi submetido à Plataforma Brasil e aprovado (Certificado de Apresentação para Apreciação Ética - CAAE: 43342515.1.0000.5237).

Os sujeitos da pesquisa são os alunos de quatro turmas, aqui chamadas $A, B, C$ e D, do primeiro ano do ensino fundamental de uma escola particular de Volta Redonda, $R J$, e sua professora-pesquisadora. Foi feito um tratamento diferente para cada uma das quatro turmas, de modo que se pudesse ter uma visão da relação entre a sequência de atividades propostas e a percepção ambiental. Para decidir o que cada turma teria, houve um sorteio, visando garantir imparcialidade às escolhas.

As turmas $A, B$ e $C$ tiveram momentos de atividades lúdicas sensório-perceptivas, por meio da vivência na natureza ( $A$ e C) ou simulação na sala de aula, utilizando o produto Simulacron (A e B), objetivando potencializar os sentidos da visão, audição, tato e olfato. A turma $D$ participou somente da aula de Arte, igual para todas as turmas, em que os alunos fizeram desenhos, tendo como tema o meio ambiente. 
A seguir, podemos observar o Quadro 1 com o cronograma de atividades. Chamamos vivência, as aulas em área de proteção ambiental; simulação, as aulas com o Simulacron, na sala de aula; artes são as aulas comuns aos quatro grupos, em que foram feitos os desenhos.

Quadro 1 - Cronograma de atividades

\begin{tabular}{|c|c|c|c|c|c|}
\hline \multicolumn{5}{|c|}{ JUNHO / 2015} & \multirow[b]{2}{*}{12} \\
\hline & 8 & 9 & 10 & 11 & \\
\hline \multicolumn{6}{|c|}{ TURMA } \\
\hline & SEGUNDA & TERÇA & QUARTA & QUINTA & SEXTA \\
\hline A & & Vivência & Simulação & & Artes \\
\hline B & Simulação & Artes & & & \\
\hline $\mathrm{C}$ & & Vivência & & & Artes \\
\hline D & Artes & & & & \\
\hline
\end{tabular}

Fonte: dos autores, 2015.

É importante esclarecer que as atividades sensório-perceptivas visam aflorar, nos alunos, um sentimento de maior interação com a natureza e não uma preparação direta deles para as aulas de Artes. Lembramos que os grupos foram separados, por sorteio, para possibilitar a observação de possíveis diferenças de percepção ambiental entre os grupos nos desenhos, conforme tenham tido ou não a experiência completa.

Segundo Neiman (2007), a percepção e a própria educação devem possibilitar a expansão da consciência por meio do envolvimento afetivo das pessoas com a natureza e a cultura local. Para que esse objetivo pudesse ser atingido, os alunos das turmas $\mathrm{A} e \mathrm{C}$ foram levados a uma área de preservação ambiental e submetidos a procedimentos simples, envolvendo os sentidos, de modo que as diferentes nuances da natureza pudessem ser apreendidas. Para tal, foi selecionada uma atividade lúdica sensório-perceptiva originalmente apresentada por Cornell (2008) e adaptada para as realidades ambiental e educacional do local e do grupo a ser estudado.

$\mathrm{Na}$ etapa seguinte, a da aula simulada com as turmas A e B, foi utilizado o produto desenvolvido para esse fim, uma Publicação Digital denominada Simulacron, para ser utilizada em Ipads, Tablets e Desktops. As Publicações Digitais são a versão eletrônica de uma publicação impressa, porém com recursos de tecnologia e interatividade, tornando-se semelhantes a um aplicativo. O Simulacron contém imagens e sons selecionados da natureza para simular o ambiente natural na sala de aula, para que, através da recepção de informações sensoriais (imagens e sons), seja possível potencializar os sentidos da audição e da visão, visando estimular a percepção ambiental nos alunos.

As 21 imagens contidas no aplicativo são densas de informações significativas sobre a natureza, importantes para que se possa atingir os objetivos almejados. Essas imagens se alternam a cada 6 segundos automaticamente. No canto inferior esquerdo da tela, há três ícones em forma de setas que, uma vez acionadas individualmente, fazem rodar uma sequência de sons originais do local onde as fotos foram feitas. A sequência de imagens e sons pode ser utilizada de modo contínuo, garantindo uma aplicação adaptável a todo tipo de utilização, assim como ao comportamento dos alunos durante 
a aula simulada. Quanto maior o nível de concentração das turmas, mais vezes a sequência de imagens e sons pode ser repetida.

Finalmente, na aula de Artes,cada aluno das quatro turmas fez um desenho representando o seu entendimento de meio ambiente. 0 tempo determinado para cumprir a tarefa foi de trinta minutos.

\subsection{Do tratamento do corpus}

A coleta e a análise dos dados ocorreram no período de junho a agosto de 2015 . Um total de 78 crianças participou da pesquisa. Todos são alunos do primeiro ano do ensino fundamental, divididos em quatro turmas. Tecnicamente os alunos de todas essas turmas têm o mesmo histórico de formação na escola, sendo considerados com o mesmo potencial para análise, assim como têm a mesma faixa etária, entre seis e sete anos, que corresponde à fase de desenvolvimento gráfico proposta por Luquet (1979), denominada realismo intelectual.

O corpus da pesquisa são os desenhos dos alunos e, para a análise quantitativa, aqui denominada Análise Discreta, foi utilizada a metodologia proposta por Pedrini (2010), que busca a identificação de presença/ausência de elementos socioambientais para verificar se o sujeito estudado percebe seu meio e suas interrelações de dependência. Para essa análise, foram estabelecidas as seguintes categorias: elementos concreto natural, concreto artificial e abstrato.

$\mathrm{Na}$ categoria dos elementos concreto natural, foram identificados cinco grupos de elementos: humano, fauna, flora, atmosfera e solo. Na categoria dos elementos concreto artificial, foram identificados dois grupos de elementos: objetos e casa. Os elementos identificados na categoria abstrato foram selecionados por estarem descontextualizados. São eles: coração, personagem, rabisco e planeta.

A Tabela 1, a seguir, mostra a composição geral e a quantificação dos elementos da categoria concreto natural, apresentados nos desenhos das quatro turmas.

Tabela 1 - Quantificação dos elementos da categoria concreto natural para a composição das aulas: V - Vivência; S - Simulacron; A - Artes.

\begin{tabular}{cccccccccc}
\hline & \multicolumn{1}{c}{ CONCRETO } & NATURAL & & & \\
\hline Turmas & & humano & fauna & flora & atmosfera & solo & total & alunos & média \\
\hline A & V/S/A & 16 & 13 & 43 & 38 & 9 & 119 & 22 & 5,41 \\
\hline B & S/A & 11 & 9 & 39 & 33 & 10 & 102 & 18 & 5,67 \\
\hline C & V/A & 14 & 11 & 48 & 40 & 9 & 122 & 22 & 5,55 \\
\hline D & A & 4 & 6 & 26 & 33 & 7 & 76 & 16 & 4,75 \\
\hline
\end{tabular}

Fonte: dos autores, 2015.

No gráfico mostrado na Figura 1, baseado nos dados da Tabela 1, vê-se claramente que a participação das turmas $A, B$ e $C$ nas atividades lúdicas sensório-perceptivas contribuiu para que houvesse reflexos favoráveis na sua percepção ambiental no momento da produção dos desenhos.

O resultado observado na turma $B$, em que foi usado o aplicativo Simulacron, indica a viabilidade do produto, já que os números mostram valores tão expressivos quanto àqueles da turma $\mathrm{C}$, que participou da vivência, e da turma A, que participou da vivência e da simulação com o aplicativo Simulacron. 
Figura 1 - Apresentação dos dados do número médio de elementos concreto natural.

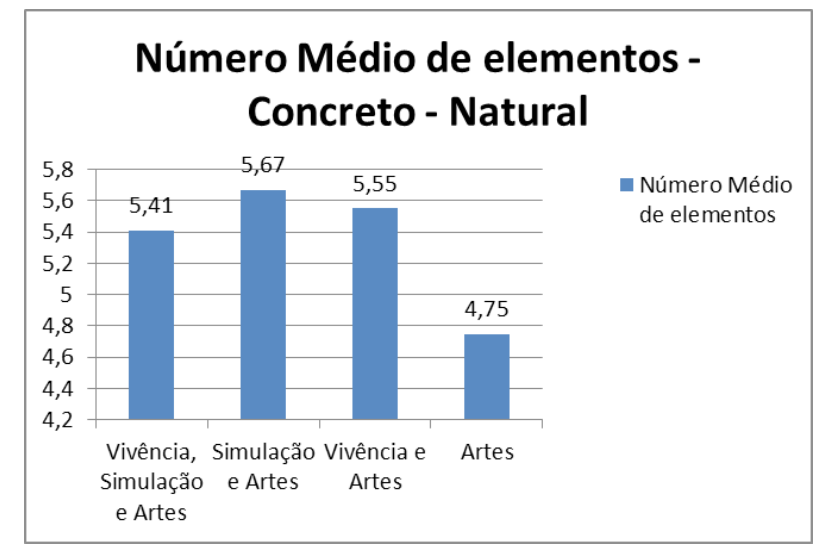

Fonte: dos autores, 2015

Dando prosseguimento à Análise Discreta, identificamos os elementos presentes na categoria concreto artificial. A Tabela 2, a seguir, mostra a composição geral e a quantificação dos elementos apresentados nos desenhos das quatro turmas.

Tabela 2 - Quantificação dos elementos da categoria concreto artificial para a composição das aulas: V -Vivência; S - Simulacron; A - Artes.

\begin{tabular}{|c|c|c|c|c|c|c|}
\hline & & & CONCRETO & ARTIFICIAL & & \\
\hline Turmas & & objeto & casa & total & alunos & média \\
\hline A & $\mathrm{V} / \mathrm{S} / \mathrm{A}$ & 20 & 4 & 24 & 22 & 1,09 \\
\hline B & $S / A$ & 15 & 8 & 23 & 18 & 1,28 \\
\hline C & $\mathrm{V} / \mathrm{A}$ & 18 & 13 & 31 & 22 & 1,41 \\
\hline D & A & 9 & 8 & 17 & 16 & 1,06 \\
\hline
\end{tabular}

$\mathrm{Na}$ análise da categoria concreto artificial, observamos que as turmas $\mathrm{A}, \mathrm{B}$ e C que participaram das atividades sensório-perceptivas, sejam pelo Simulacron ou pela vivência, também se destacaram nos resultados dos números obtidos em comparação com os resultados da turma $\mathrm{D}$, que participou somente na produção dos desenhos. Porém, no gráfico mostrado na Figura 2, a seguir, baseado nos dados da Tabela 2, observamos que as diferenças entre os valores obtidos nas quatro turmas não têm o mesmo impacto que os valores obtidos na categoria anterior. Portanto, essa análise é considerada apenas como uma leve tendência. 
Figura 2 - Número médio de elementos Concreto-Artificial

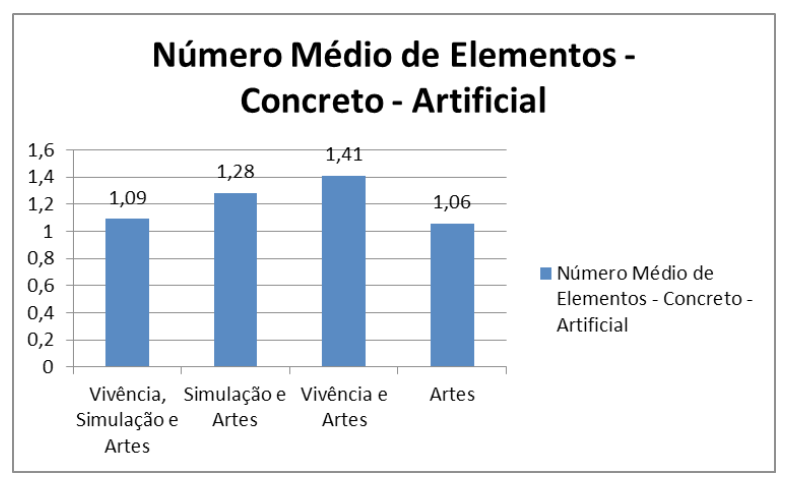

Fonte: dos autores, 2015.

Na Figura 3, a seguir, um gráfico completo apresenta todas as categorias para comparação entre as turmas e é destacada a preponderância da categoria concreto natural sobre todas as demais categorias, seja qual for a participação das turmas nas atividades propostas.

Figura 3 - Média de elementos da Análise Discreta.

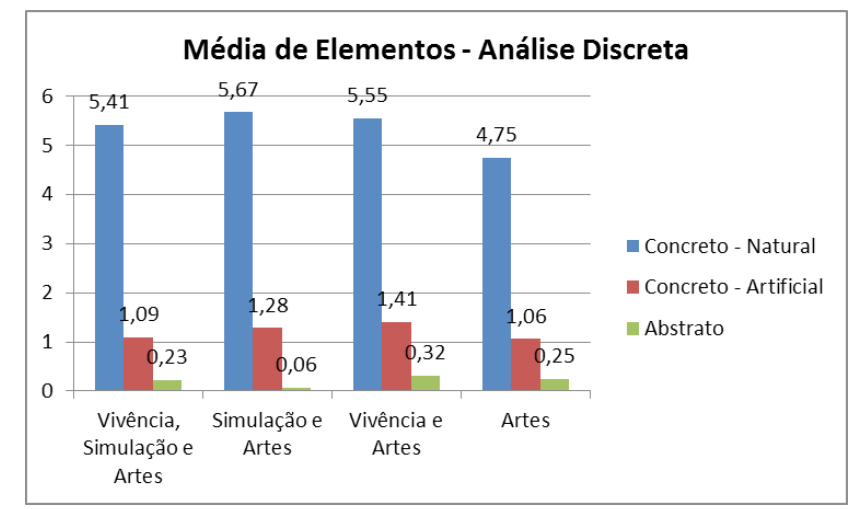

Fonte: dos autores, 2015.

Esse resultado também é destacado nos trabalhos de Garrido e Meirelles (2014) e de Pedrini, Costa e Ghilardi (2010), confirmando a aplicabilidade do método no presente trabalho, ou seja, percebe-se que, na comparação entre a diagramação das três categorias, a categoria concreto natural tem maior destaque nas quatro turmas, enquanto a categoria abstrato não apresenta um resultado significativo. De acordo com Pedrini, Costa e Ghilardi (2010), o resultado da categoria abstrato evidencia que a percepção de meio ambiente é mais o que é visto do que o não visto.

Para a análise qualitativa dos desenhos, aqui denominada Análise do Continuum, utilizamos a classificação proposta por Reigota (2010). Segundo o autor, o conceito de meio ambiente é dividido em três tipos: naturalista, meio como sinônimo de natureza intocada, caracterizado pelos aspectos naturais; antropocêntrico, meio como fonte de recursos para a sobrevivência; e globalizante, meio integrado pela natureza e sociedade. A pesquisa qualitativa parte do pressuposto de que as pessoas agem em função de suas crenças, percepções, sentimentos e valores e que, para todo comportamento humano, há um sentido, uma interpretação (MINAYO, 1998). Para essa análise, o desenho foi observado como um todo, buscando uma visão ampla dos elementos representados. 0 desenho considerado como sendo do tipo 
globalizante foi aquele em que o elemento homem estava presente; o tipo naturalista foi aquele com a presença dos elementos fauna e flora $e$ a ausência do elemento homem; o tipo antropocêntrico, há a presença dos elementos artificias, dos elementos fauna e flora e a ausência do elemento homem nos desenhos.

Para a Análise do Continuum, observamos que as turmas A, B e C, que participaram das atividades sensório-perceptivas, tiveram um percentual elevado de desenhos do tipo globalizante, quando comparadas com a turma $\mathrm{D}$, que participou somente da aula de Artes.

Figura 4 - Percentual do tipo Globalizante.

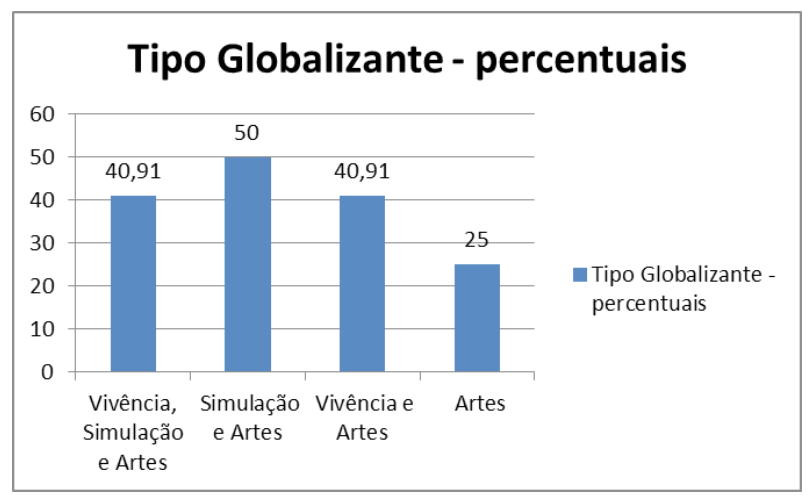

Fonte: dos autores, 2015.

O gráfico representado na Figura 4 mostra um aumento percentual considerável de desenhos do tipo globalizante. De $25 \%$ para a turma $D$, que não teve a exposição aos elementos da natureza, para $40,91 \%$ para a turma A, $40,91 \%$ para a turma C e $50 \%$ para a turma B, que tiveram exposição aos elementos da natureza através das atividades lúdicas sensório-perceptivas e do aplicativo Simulacron.

Também fica destacado, observando os dados no gráfico da Figura 5 a seguir, que as turmas $\mathrm{A}$, B e C, que participaram das atividades sensório-perceptivas, tiveram a preponderância de desenhos do tipo Globalizante, quando comparados com os desenhos dos tipos Naturalista e Antropocêntrico.

Figura 5 - Percentuais da tipologia por turma.

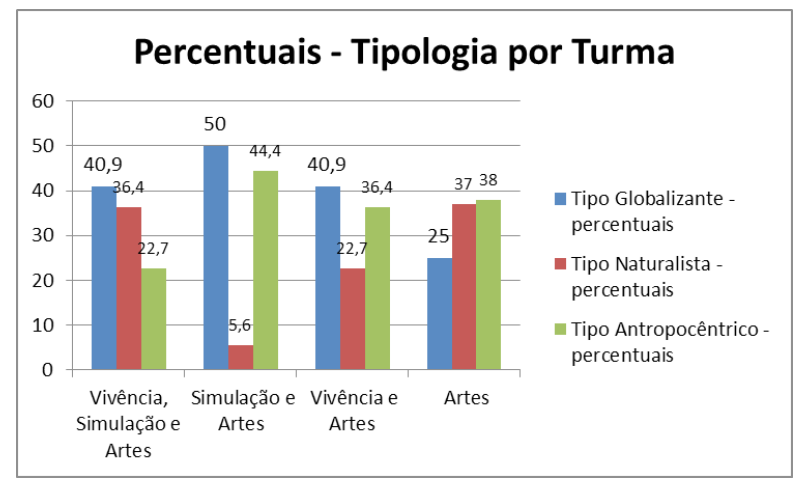

Fonte: dos autores, 2015

É importante destacar que, em vários trabalhos (FERREIRA; NETO, 2009; PEDRINI; COSTA; GHILARDI, 2010; GARRIDO; MEIRELLES, 2014), a inferioridade nos resultados dos desenhos do tipo globalizante 
é confirmada. Vê-se aqui a força de transformação na percepção dos alunos, quando expostos às atividades sensório-perceptivas desenvolvidas e aplicadas para esse fim.

\section{CONSIDERAÇÕES FINAIS}

Na busca por sociedades ambientalmente mais responsáveis, encontramos na educação ambiental uma estratégia para alcançar esse objetivo, sendo a escola o espaço ideal para o desenvolvimento de ações que estimulam o sonhar com mudanças possíveis. Porém, o desafı é como inserir a prática da educação ambiental na escola de maneira eficaz e envolvente, através de atividades desenvolvidas no contexto escolar, com o objetivo de estimular nos alunos sentimentos positivos que, posteriormente, possam gerar atitudes positivas em relação ao ambiente em que vivemos.

Sendo assim, a escolha do tema para o desenvolvimento desta pesquisa se deu a partir do interesse em saber o quanto o desenvolvimento da percepção ambiental dos alunos da série inicial do ensino fundamental pode servir de auxílio para despertar uma consciência ecológica mais ampla, já que um dos objetivos da educação ambiental é fazer com que os alunos se sintam como parte integrante do meio ambiente.

A análise dos desenhos constituiu-se em um mergulho no imaginário dos alunos, possibilitando conhecer o seu mundo real, já que, para a criança, o desenho é uma forma de comunicação e também uma maneira de expressar o meio onde habita. A utilização de uma adaptação de dois procedimentos consagrados nos estudos sobre a representação de meio ambiente por meio do desenho infantil, mostrou-se adequada para a identificação de percepção ambiental dos alunos. Por intermédio de um sistema de aulas em que quatro turmas participaram de atividades selecionadas, foi possível comparar os seus desenhos, conforme tenham tido ou não a experiência completa.

Os resultados aqui descritos foram reveladores. Há de se destacar que a utilização de atividades sensório-perceptivas, in loco e/ou em sala de aula com o aplicativo Simulacron, fez com que os índices relativos aos valores ambientais fossem elevados. Com os resultados obtidos na média dos elementos da Análise Discreta (Figura 3), afırmamos a viabilidade do produto, observável com base nos mesmos níveis de resultado da turma que utilizou o aplicativo Simulacron comparados com o resultado da turma que participou das atividades sensório-perceptivas in loco.

Nos resultados que representam os percentuais de tipologia ambiental por turma da Análise do Continuum (Figura 5), vemos que as turmas que participaram das atividades sensório-perceptivas in loco e/ou em sala de aula com a utilização do aplicativo Simulacron tiveram um percentual elevado de desenhos do tipo Globalizante, quando comparadas com a turma que participou somente da aula de Artes. Esse resultado corrobora a importância da inserção de ações de educação ambiental na escola por meio de atividades sensório-perceptivas, sejam elas in loco e/ou simuladas em sala de aula, no desenvolvimento da percepção dos alunos, fazendo com que entendam a sua importância e a de cada componente do ambiente para o equilíbrio planetário.

Portanto, diante dos resultados expostos, o aplicativo Simulacron, aqui apresentado, pode ser considerado uma alternativa para complementar, potencializar ou até mesmo, em alguns casos, substituir aulas in loco, facilitando o desenvolvimento e execução de ações em educação ambiental. 


\section{REFERÊNCIAS}

BRASIL. Ministério da Educação e do Desporto. Secretaria de Educação Fundamental. Parâmetros curriculares nacionais: meio ambiente e saúde. Brasília: MEC/SEF, 128p, 1997.

CAPRA, F. A teia da vida. São Paulo: Cultrix, 1996.

COLETO, D. C. A importância da arte para a formação da criança. Revista Conteúdo, Capivari, v.1, n.3, p. 137-152, jan/jul 2010.

CORNELL, J. Vivências com a natureza. São Paulo: Aquariana, 2008.

DOUBRAWA A.; NOLASCO M. A. Avaliação de uma trilha interpretativa monitorada como instrumento de aprendizagem em educação ambiental. Educação ambiental em ação, Novo Hamburgo, RS, n.31, 2010.

ENGEL, G. I. Pesquisa-ação. Educar, Curitiba, n. 16, p. 181-191. Editora da UFPR, 2000.

FERREIRA, G.; NETO, G. G. Interpretando desenhos de crianças para verificar sua inserção no ambiente. Revista Brasileira de Educação Ambiental/Rede Brasileira de Educação Ambiental. Cuiabá, n.4, jul. 2009.

GADOTTI, M. Boniteza de um sonho: ensinar-e-aprender com sentido. São Paulo: Ed. Cortez, 2002.

GARRIDO, L.; MEIRELLES, R.Percepção sobre meio ambiente por alunos das séries iniciais do Ensino Fundamental: considerações à luz de Marx e de Paulo Freire. Ciência \& Educação, Bauru, online, 2014. Disponível em: <http://www.redalyc.org/articulo.oa?id=251031804010>. Acesso: 2 jun. 2015.

GOLDBERG, L. G.; YUNES, M. A. M \& FREITAS, J. V. de. O desenho infantil na ótica da ecologia do desenvolvimento humano. Psicologia em estudo, Maringá. v. 10, n. 1, p. 97-106, jan./abr. 2005.

JACOBI, P. Educação Ambiental, cidadania e sustentabilidade. Cadernos de Pesquisa, n. 118, março/ 2003. Disponível em: <http://www.scielo.br/pdf/cp/n118/16834.pdf>. Acesso em 10 jan. 2015.

LUQUET, G. H. O desenho infantil. Trad. Maria Teresa Gonçalves de Azevedo. Porto: Livraria Civilização, 1979.

MARIN, A. A. Percepção ambiental e imaginário dos moradores do município de Jardim/MS. 2003, $317 f$. Tese de doutorado, Ecologia e Recursos Naturais. São Carlos: UFSCar, 2003.

MAROTI, P. S. Percepção e Educação Ambiental voltadas à uma unidade natural de conservação (Estação Ecológica de Jataí, Luiz Antônio, SP). São Carlos: Universidade Federal de São Carlos - UFSCar (Dissertação), 1997.

MATOS, L. F. de O. R. Percepção ambiental de estudantes de uma escola da região central de Cuiabá, MT. Cuiabá: Universidade Federal de Mato Grosso - UFMT (Dissertação), 2009.

MÈREDIEU, F. 0 desenho infantil. São Paulo: Cultrix, 2006.

MINAYO, M. C. S. Ciência, técnica e arte: o desafio da pesquisa social. In: MINAYO, M. C. S. (Org.). A pesquisa social: teoria, método e criatividade. 9ed. Rio de Janeiro: Petrópolis, 1998. p. 9-29. 
MORIN, E. A noção de sujeito. In: SCHNITMAN, D. F.(Org.).Novos paradigmas, cultura e subjetividade (p.45-58). Porto Alegre: Artes Médicas, 1996.

NEIMAN, Z. A Educação Ambiental através do contato dirigido com a natureza. Doutorado, Psicologia Experimental, USP, 2007.

OLIVEIRA, I. B. de Contribuições de Boaventura de Souza Santos pra a reflexão curricular: princípios emancipatórios e currículos pensados praticados. Revista e-curriculum, São Paulo, v.8, n.2,ago 2012.

PEDRINI, A. Percepção ambiental de crianças e pré-adolescentes em vulnerabilidade social para projetos de educação ambiental. Ciência e Educação, Bauru, v.16, n.1, p.163-179, 2010.

PIAGET, J. A equilibração das estruturas cognitivas. Rio de Janeiro: Zahar, 1976.

REIGADA, C.; TOZONI-REIS, M. F. C. Educação ambiental para crianças no ambiente urbano:uma proposta de Pesquisa-Ação. Ciência \& Educação, Bauru, v.10, n.2, p.149-159, 2004.

REIGOTA, M. Meio ambiente e representação social. 8. ed. São Paulo: Cortez, 2010.

THIOLLENT, M. Metodologia da Pesquisa-Ação. 11. ed. São Paulo: Cortez, 2002.

TOZONI-REIS, M. F. C. Pesquisa-ação em Educação Ambiental. Pesquisa em Educação Ambiental, São Paulo, vol.3, n.1, p.155-169, 2008.

TRIPP, D. Pesquisa-ação: uma introdução metodológica Educação e Pesquisa. Educação e Pesquisa, São Paulo, v. 31, n. 3, p. 443-466, set./dez. 2005.

TRISTÃO, M. Tecendo os fios da educação ambiental: o subjetivo e o coletivo, o pensado e o vivido. Educação e Pesquisa, São Paulo, v. 31, n. 2, p. 251-264, maio/ago. 2005.

TUAN, Y. Topofolia: um estudo da percepção, atitudes e valores do meio ambiente. São Paulo: Difel, 1980.

VYGOTSKY, L. S. O desenvolvimento psicológico na infância. 3. ed. São Paulo: Martins Fontes, 2003. Pensamento e linguagem. São Paulo: Martins Editora, 2009. 